\title{
Morbidity and functional mid-term outcomes using Prolift pelvic floor repair systems
}

\author{
Sébastien Kozal, MD; Thomas Ripert, MD; ${ }^{*}$ Younes Bayoud, MD; ${ }^{*}$ Johan Menard, MD;* \\ loannis Nicolacopoulos, MD;" Laurence Bednarzyck, MD;; Frederic Staerman, MD, ${ }^{*_{ \pm}}$Stéphane Larré, MD*
}

*Department of Urology and Andrology. Robert Debré, University Hospital, Reims, France; 'Department of Urology and Andrology, Polyclinic Courlancy, Reims, France; §Department of Urology, Manchester General Hospital, Charleville, France; *Department of Obstetrics and Gynecology, Manchester General Hospital, Charleville, France; ‘Departement of Urology and Andrology, Polyclinic Les Bleuets, Reims, France

Cite as: Can Urol Assoc J 2014;8(9-10):e605-9. http://dx.doi.org/10.5489/cuaj.2022 Published online September 9, 2014.

\section{Abstract}

Introduction: We assess midterm morbidity and functional outcomes using the Prolift (Gynecare/Ethicon, Somerville, NJ) system and identify potential related risk factors. The Prolift mesh system to treat genital prolapse was introduced in 2005. It was withdrawn from the market in early 2013 after rising doubts about safety.

Methods: Over a 7-year period, we retrospectively analyzed a cohort of 112 consecutive patients who underwent the Prolift procedure since 2006. Intraoperative and postoperative complications, anatomical and functional outcomes were recorded.

Results: The median follow-up was 49.5 months (range: 16-85). The mean age was $64.7 \pm 10.9$ years (range: $40-86$ ). Of the 112 patients, 74 patients had stage $3(66.1 \%)$ and 8 patients had stage $4(7.14 \%)$ vaginal prolapse. Prolift surgery was performed for prolapse recurrence for 26 patients (23.2\%). Total mesh was used in 32 patients $(29 \%)$, an isolated anterior mesh in 57 patients $(51 \%)$ and an isolated posterior mesh in 23 patients (21\%). Concomitant surgical procedures were performed for 44 patients (39.3\%). Overall, $72 \%(18 / 25)$ of the complications were managed medically. We reported a failure rate of $8 \%(n=9)$ occurring after a median followup of 9.5 months (range: $1-45$ ). Among the 64 patients who had preoperative sexual activity (57.1\%), de novo dyspareunia occurred in 9 patients $(16.07 \%)$. We extracted predictive factors concerning failure, complications and sexuality.

Conclusion: Despite its market withdrawal, the Prolift system was associated with good midterm anatomic outcomes and few severe complications. Long-term follow-up data are still lacking, but surgeons and patients may be reassured.

\section{Introduction}

With over 200000 surgeries performed yearly, pelvic organ prolapse $(\mathrm{POP})$, often associated with stress urinary inconti- nence, is a major health concern, especially for parous and elderly women. ${ }^{1}$ Numerous abdominal and vaginal surgical techniques are available to treat POP. Sacrocolpopexy through abdominal approach uses a synthetic mesh to resuspend the vaginal vault. It is the most commonly used technique with a long-term success rate above $90 \% .^{2}$ Transvaginal placation techniques are also available to treat POP. They are less invasive requiring a shorter recovery time, but are associated with a higher recurrence rate. ${ }^{3,4}$ They are commonly used in elderly women, with multiple medical comorbidities or relative contraindications to the abdominal approach.

The Prolift system (Gynecare/Ethicon, Somerville, NJ) is another vaginal technique to merge the benefits of both approaches. It is composed of a low-weight $\left(42.7 \mathrm{~g} / \mathrm{m}^{2}\right)$, thin $(0.42 \mathrm{~mm})$ and high-porosity $(64 \%)$ one-thread preformed polypropylene prosthesis synthetic graft retrofitted with arms. It is used instead of native tissue to correct the POP. ${ }^{5}$ The use of transvaginal mesh techniques is nonetheless associated with specific complications, including infection, mesh erosion, abdominal organs or vessels injuries, and vaginal scarring. ${ }^{6,7}$ There is limited and no long-term data on outcomes using the Prolift system and concerns were recently raised about its safety. Nonetheless, since 2008, the FDA ordered the manufacturer to demonstrate the safety and efficacy of the product and the manufacturer finally opted to withdraw Prolift and other mesh systems from the market in 2012. Many concerns have been raised by the FDA and patients who report recurrent POP, severe chronic pelvic pain and de novo dyspareunia possibly related to mesh erosion or retraction. As a result, class actions have been launched in the United States and Australia. The aim of this study was to report the long-term complication rates and functional outcomes associated with the Prolift system based on 7 years of experience at 2 French centres. 
Kozal et al.

\section{Methods}

We retrospectively reviewed data from medical records from October 2005 to December 2012 at the Reims Robert Debré academic hospital and Charleville Manchester General hospital in France. All women presenting with POP and treated with the Prolift system were included. Medical history, prior prolapse surgery and urinary incontinence history, and physical examination were recorded. Urodynamic evaluation was performed at the discretion of the clinician according to medical history, symptoms or clinical examination. POP was quantified preoperatively and during follow-up using the POP-quantification (POP-Q) system, as recommended by the International Continence Society. ${ }^{8}$ The surgical technique was similar for all surgeons and followed product guidance. ${ }^{9}$ We recorded concomitant procedure, intra-operative and postoperative complications, anatomi$\mathrm{cal}$ and functional outcomes. Postoperative gynecological examination was performed at months 1, 3, 6 and 12 and then yearly. Failure was defined as a recurrent prolapse stage $\geq 2$ or any symptomatic prolapse. We also recorded de novo prolapse of an initially unaffected and non-treated vaginal compartment.

In addition to their annual physical examination, all women were contacted by phone in December 2013 to reassess their health status and to see whether any complications occurred or if they required any procedure related to their initial prolapse surgery. They were asked the following questions: "Were you sexually active before surgery?," "Are you sexually active at the present time?" and "Do you have any pain during intercourse?" When applicable, the type of dyspareunia was also recorded (at insertion, deep penetration or throughout intercourse).

Statistical analysis was performed using Statview 5.0. The results were considered significant at $p<0.05$.

\section{Results}

The Prolift system was used to treat POP for 112 women. The median follow-up was 49.5 months (range: 16-85) and the mean age was 64.7 years. The procedures were performed by 7 urologists and 7 gynecologists. The median number of procedures per surgeons was 5 (range: 1-24) (Table 1).

Stage 3 or 4 cystocele represented $64 \%$ of the cystoceles observed. Similarly stage 3 and 4 colpocele and rectocele were observed in $30 \%$ and $33 \%$ of the colpocele and rectocele observed, respectively (Table 2 ).

In total, 26 women $(23.2 \%)$ had the Prolift procedure because of a recurrence of a previously treated POP. Previous treatment included sacrocolpopexy $(n=9)$, sacrocolpopexy and Burch $(n=2)$, Burch $(n=1)$, sacrocolpopexy and myorraphy $(n=1)$, myorraphy $(n=2)$, absorbable mesh $(n=2)$, sacrospinous fixation $(n=5)$, sacrospinous fixation and myorraphy $(n=3)$, and Marshall-Marchetti-Krantz $(n=1)$.

\begin{tabular}{|c|c|}
\hline Variable & Value \\
\hline No. patients (n) & 112 \\
\hline Mean age (years) $\pm \mathrm{SD}$ (range) & $\begin{array}{c}64.7 \pm 10.9 \\
(40-86)\end{array}$ \\
\hline Parity, median (range) & $3(0-8)$ \\
\hline BMI, median, kg/m2 (range) & $26.25(15-41.5)$ \\
\hline Previous prolapse surgery, $\mathrm{n}(\%)$ & $26(23 \%)$ \\
\hline Previous hysterectomy, n (\%) & $38(33 \%)$ \\
\hline $\begin{array}{l}\text { Menopausal status, } \mathbf{n}(\%) \\
\text { Premenopausal } \\
\text { Postmenopausal with hormone therapy } \\
\text { Postmenopausal without hormone therapy }\end{array}$ & $\begin{array}{l}10(9 \%) \\
7(6.3 \%) \\
95(85 \%)\end{array}$ \\
\hline $\begin{array}{l}\text { Smoking status, } \mathbf{n}(\%) \\
\text { Smoker } \\
\text { Non-smoker }\end{array}$ & $\begin{array}{c}9(8 \%) \\
103(92 \%)\end{array}$ \\
\hline Median postoperative follow-up, months (range) & $49.5(16-85)$ \\
\hline Previous POP treatment, $\mathrm{n}(\%)$ & $26(23 \%)$ \\
\hline $\begin{array}{l}\text { Prolift technique used, } \mathbf{n}(\%) \\
\text { Anterior mesh } \\
\text { Posterior mesh } \\
\text { Anterior and posterior mesh }\end{array}$ & $\begin{array}{l}57(51 \%) \\
23(21 \%) \\
32(29 \%)\end{array}$ \\
\hline Associated surgery, n (\%) & $44(39 \%)$ \\
\hline Mean operating room time, min (range) & $74(25-195)$ \\
\hline Mean blood loss, $\mathrm{mL}$ ( range) & $60(50-250)$ \\
\hline $\begin{array}{l}\text { Type of anesthesia, } \mathbf{n}(\%) \\
\text { General } \\
\text { Spinal }\end{array}$ & $\begin{array}{l}87(78 \%) \\
25(22 \%)\end{array}$ \\
\hline Mean hospital stay, days (range) & $4.3(2-7)$ \\
\hline Mean urinary catheter duration, days (range) & $2.05(1-10)$ \\
\hline $\begin{array}{l}\text { Cystocele } \\
\text { Stage } 0-1 \\
\text { Stage } 2 \\
\text { Stage } 3 \\
\text { Stage } 4\end{array}$ & $\begin{array}{c}94(84 \%) \\
8 \\
26 \\
54 \\
6\end{array}$ \\
\hline $\begin{array}{l}\text { Colpocele } \\
\text { Stage } 0-1 \\
\text { Stage } 2 \\
\text { Stage } 3 \\
\text { Stage } 4\end{array}$ & $\begin{array}{l}37(31 \%) \\
10 \\
16 \\
10 \\
1\end{array}$ \\
\hline Enterocele & $5(4.5 \%)$ \\
\hline $\begin{array}{l}\text { Rectocele } \\
\text { Stage } 0-1 \\
\text { Stage } 2 \\
\text { Stage } 3 \\
\text { Stage } 4\end{array}$ & $\begin{array}{l}66(59 \%) \\
22 \\
21 \\
21 \\
2\end{array}$ \\
\hline
\end{tabular}

SD: standard deviation; BMI: body mass index; POP: pelvic organ prolapse.

Half of the patients treated with Prolift had anterior and posterior techniques, while the remaining patients had only the anterior compartment. Additional surgical procedures were performed at the same time for 44 patients $(39.3 \%)$. These included urethral slings $(n=26)$, hysterectomy $(n=6)$, myorraphy $(n=3)$, sacrospinous fixation $(n=8)$ and hernia repair $(n=1)$. 


\begin{tabular}{lc}
\hline \multicolumn{2}{l}{ Table 2. Perioperative and postoperative complications } \\
\hline Complications & $\mathbf{n}(\%)$ \\
\hline Perioperative complications & \\
Bladder perforation & $3(2.7 \%)$ \\
Rectum perforation & 0 \\
Transfusion & 0 \\
Postoperative and late complications & $25(22 \%)$ \\
Defecation disorders & $12(11 \%)$ \\
Urinary tract infection & $2(1.7 \%)$ \\
Urinary retention & $2(1.7 \%)$ \\
Infections & $2(1.7 \%)$ \\
Chronic pain syndrome & $2(1.7 \%)$ \\
Mesh exposure & $5(4.5 \%)$ \\
Clavien classification & \\
I & $2(1.7 \%)$ \\
II & $16(14.3 \%)$ \\
IIla & $2(1.7 \%)$ \\
Illb & $5(4.5 \%)$ \\
IV, V & 0 \\
\hline
\end{tabular}

\section{Complications and sexual outcomes}

No transfusion or bleeding greater than $250 \mathrm{~mL}$ was reported. Three bladder injuries $(2.5 \%)$ were observed (Table $2)$, which were immediately repaired transvaginally with favourable outcomes. Postoperative complications covering the full follow-up period occurred in 25 patients (22\%). Clavien grade I or II complications occurred in 18 patients $(16 \%)$ and grade III in 7 patients $(6 \%)$. No grade IV or V complications were observed. The most common complication was defecation disorders (10.7\%). Surgical management of postoperative complications was required for 5 patients $(4.5 \%)$ who had mesh exposure. These occurred for 2 out of 14 surgeons: 1 urologist at the fourth procedure out of 18, and 1 gynecologist at the second, ninth and 14th procedure out of 15 . All 5 patients, except for 1 , were successfully managed with resection. One patient required ablation after a secondary retraction at 45 months.

Among the 64 patients who were sexually active before surgery, $8(12.5 \%)$ were not sexually active postoperatively. Reasons reported were meshes retraction $(n=2)$, POP recurrence $(n=2)$, lack of partner $(n=2)$, lack of pleasure $(n=1)$ and unknown $(n=1)$. None of the non-sexually active women became sexually active after surgery. Most of the preoperative sexually active women $(78.6 \%)$ had no modification in their sexual activity postoperatively. For those reporting a decline $(16.1 \%)$, this was related to de novo dyspareunia occurring at insertion $(n=5)$, deep penetration $(n=1)$ or intercourse $(n=3)$. Three patients reported a better quality in sexual activity after surgery.

\section{Functional outcomes}

Success for the treated compartment was observed in 103 patients (92\%) (Table 3). Failure occurred in 9 patients after a median follow-up of 9.5 months (range: 1-45). The occurrence of a de novo prolapse was observed in 13 patients $(11.6 \%)$ in an initially non-treated compartment. These included 7 rectoceles, 2 cystoceles and 4 colpoceles.

We identified significant clinical differences in patients regarding results, complications or sexuality (Table 4). We also found that de novo prolapses occurred more often in younger patients (mean age 58.3 vs. $65.2, p=0.03$ ).

\section{Discussion}

This study reported midterm outcomes using the Mesh repair system for POP. This study confirms that the good success rate of the procedure reported previously (87\%-97\%) after 3 to 12 months ${ }^{10}$ of follow-up is maintained after 3 years (92\%).

Prolapses distribution in terms of stage, population or POP-Q classification, is similar in our study compared to other studies in literature. ${ }^{9}$ Polypropylene meshes may therefore be more adapted than biological meshes, for which a failure rate of $41 \%$ is observed at 3 years follow-up. ${ }^{11}$

Synthetic and biological prostheses have been developed and marketed often in the absence of well-conducted randomized controlled studies. ${ }^{12}$ The best material needs high porosity, large pore size and a low thin band to allow colonization by fibroblasts and fix prostheses. No thread is needed. There is a consensus in favour of the polypropylene monofilament mesh. ${ }^{13}$ Ethicon developed Prolift $+M$ secondly and this mesh contained $28 \mathrm{~g} / \mathrm{m}^{2}$ polypropylene and monocryl versus $42.7 \mathrm{~g} / \mathrm{m}^{2}$ in Prolift. ${ }^{14}$ Prolift+M could reduce inflammation, risk exposure and retractions. In our study we used only Prolift meshes. Long-term follow-up is still lacking concerning these second meshes.

There are multiple surgical techniques to address POP by vaginal or abdominal approach with or without a mesh.

\begin{tabular}{lc}
\hline Table 3. Functional and sexual outcomes & \\
\hline Data analyzed & $\mathbf{n}(\%)$ \\
\hline Prolapse occurrence after surgery & $\mathbf{2 2 ( 1 9 . 6 \% )}$ \\
De novo prolapse & $13(11.6 \%)$ \\
Recurrence & $9(8.0 \%)$ \\
Preoperative sexually active women outcomes & $\mathbf{6 4}(\mathbf{5 7} \%)$ \\
Not sexually active anymore & $8(12.5 \%)$ \\
Decline & $9(14.1 \%)$ \\
No modification & $44(68.8 \%)$ \\
Better & $3(4.7 \%)$ \\
Preoperative dyspareunic women outcomes & $\mathbf{4 ( 6 . 3 \% )}$ \\
Improved & 2 \\
Unchanged & 2 \\
Worsen & 0 \\
De novo occurrence of dyspareunia after surgery & $\mathbf{9 ( 1 6 . 1 \% )}$ \\
At insertion & 5 \\
At deep penetration & 1 \\
Throughout intercourse & 3 \\
\hline
\end{tabular}


Kozal et al.

\begin{tabular}{|c|c|c|c|c|c|c|c|c|c|}
\hline & \multicolumn{3}{|l|}{ POP results } & \multicolumn{3}{|c|}{ Complications } & \multicolumn{3}{|c|}{ De novo dyspareunia } \\
\hline & Success $(n=103)$ & Failure (n = 9) & $p$ & Yes (n = 25) & No $(n=87)$ & $p$ & Yes $(n=9)$ & No $(n=103)$ & $\boldsymbol{p}$ \\
\hline Age (mean) & 65.1 & 56.7 & 0.02 & 61.6 & 65.1 & ns & 55.5 & 65.2 & 0.009 \\
\hline BMI (mean) & 27.2 & 33 & $<0.001$ & 28.8 & 27.4 & ns & 31.3 & 27.4 & 0.035 \\
\hline Menopaused & $92.2 \%$ & $77.8 \%$ & ns & $76 \%$ & $95.4 \%$ & ns & $55.5 \%$ & $94.1 \%$ & 0.01 \\
\hline POP stage $\geq 3$ & $75.7 \%$ & $44.4 \%$ & 0.04 & $48 \%$ & $80.5 \%$ & 0.01 & $66.6 \%$ & $73.8 \%$ & NS \\
\hline
\end{tabular}

BMI: body mass index; NS: not significant; POP: pelvic organ prolapse.

Among these, non-mesh techniques have a lower success rate.

Anterior colporraphy is the gold standard to treat cystocele by the vaginal approach. Satisfying anatomic results were found - about $59 \%$ at the 2 -year follow-up, ${ }^{15}$ showing an important risk of recurrence in midterm follow-up and the importance of prosthesis. ${ }^{15}$ The sacrospinous fixations report a $67 \%$ to $97 \%$ success in hysterocele. ${ }^{16}$ The higher risk to patients treated with autologous tissues was the cystocele recurrence in $20 \%$ to $30 \% i^{17}$ this is much higher than the results of our study.

The gold standard to correct prolapses was the sacrocolpopexy, with a $94 \%$ success rate, slightly higher than the $92 \%$ success rate defined by the clinical examination. ${ }^{18}$ However, the population was not really comparable between our study and sacrocolpopexy's population and indications were not totally the same. Our population was older than population treated by sacrocolpopexy and the results concerning failure, sexuality or de novo prolapse must be validated.

Vaginal mesh exposures occurred in most patients and were part of the learning curve; ${ }^{19}$ the rate was contained between $2 \%$ to $14.4 \%{ }^{20}$ and near $2.7 \%$ in sacrocolpopexy. ${ }^{18}$ The surgical techniques may be a factor determining surgical outcome. In our study, 1 gynecological surgeon who made large colpotomy and used diathermy knife realized $80 \%$ of the meshes exposures. Large colpotomy, hysterectomy during the procedure, weak vaginal thickness and the use of diathermy knifes are risk factors to exposures. ${ }^{21}$

The "de novo" prolapses arrived in $24 \%$ after anterior myorraphy ${ }^{9}$ and in $13.8 \%$ to $17.8 \%$ after using anterior meshes.

Sexuality was not really the aim of this study, but in the literature on using the vaginal approach to correct POP, a rate of "de novo" dyspareunia in $10 \%$ to $20 \%,{ }^{10,22} 15 \%$ in sacrospinous fixation and $20 \%$ in myorraphy. ${ }^{6}$ In the literature, the rate of "de novo" dyspareunia in sacrocolpopexy is $7.8 \% .^{18}$ Multiple studies have not demonstrated any difference in surgery with or without meshes.,23,24 An advantage, however, was shown in surgery with prosthesis. ${ }^{25}$

We used a non-validated questionnaire, but a set of short questions including simple clinical data, limiting the extrapolation of our own results. We tried to find correlations between the results of POP, sexuality and complica- tions. Few studies found predictive factors in the treatment of POP. ${ }^{26,27}$ Our results confirm the existence of a learning curve; ${ }^{28}$ there is a significant difference in a surgeon with more than 10 surgeries. Stage $\geq 3$ was not a predictive factor to "de novo" dyspareunia. More explorations are needed to confirm any predictive factors.

Reported complications of rectal erosion, ${ }^{28}$ massive bleeding, ${ }^{29}$ anal incontinence ${ }^{30}$ or multiples retractions were not found in our study. We reported only 1 retraction out of the 112 procedures. Ethicon removed the Prolift system in first quarter of 2013; however, the company continues to assert its efficiency. It has removed this system after multiple collective complaints in the United States.

\section{Conclusion}

Although the Prolift system was removed from the market, it was associated with good midterm anatomic outcomes and few severe complications. The main limit was the impact on sexuality and the occurrence of de novo POP. Based on our results, better results were observed in elderly nonobese women with stage 3 or more POP. The procedure is currently offered to non-sexually active elderly women unfit for sacrocolpopexy.

Competing interests: Dr. Koza, Dr. Ripert, Dr. Bayoud, Dr. Menard, Dr. Nicolacopoulos, Dr. Bednarzyck, Dr. Staerman and Dr. Larré all declare no competing financial or personal interests.

This paper has been peer-reviewed.

\section{References}

1. Drutz HP, Alarab M. Pelvic organ prolapse: Demographics and future growth prospects. Int Urogynecol J Pelvic Floor Dysfunct 2006; 17:S6-9. http://dx.doi.org/10.1007/s00192-006-0102-1

2. Wagner L, Boileau L, Delmas V. Surgical treatment of prolapse using coelioscopic promontofixation: techniques and results [in French]. Prog Urol 2009;19:994-1005. http://dx.doi.org/10.1016/i. purol.2009.09.026

3. Maher CF, Qatawneh AM, Dwyer PL. Abdominal sacral colpopexy or vaginal sacrospinous colpopexy for vaginal vault prolapse: A prospective randomized study. Am J Obstet Gynecol 2004;190:20-6. http:// dx.doi.org/10.1016/i.ojog.2003.08.031

4. Benson JT, Lucente V, McClellan E. Vaginal versus abdominal reconstructive surgery for the treatment of pelvic support defects: A prospective randomized study with long-term outcome evaluation. Am J Obstet Gynecol 1996;175:1418-21; discussion 1421-2. http://dx.doi.org/10.1016/S00029378(96)70084-4 
5. Reisenauer C, Kirschniak A, Drews U. Anatomical conditions for pelvic floor reconstruction with polypropyene implant and its application for the treatment of vaginal prolapse. Eur J Obstet Gynecol Reprod Biol 2007;131:214-25. http://dx.doi.org/10.1016/i.ejogrb.2006.03.020

6. Kahn MA, Stanton SL. Techniques of rectocele repair and their effects on bowel function. Int Urogynecol J Pelvic Floor Dysfunct 1998;9:37-47. http://dx.doi.org/10.1007/BF01900540

7. Paraiso MFR. Surgery for apical vaginal prolapse. Curr Womens Health Rep 2002;2:285-90.

8. Persu C, Chapple CR, Cauni V. Pelvic Organ Prolapse Quantification System (POP-Q): A new era in pelvic prolapse staging. J Med life 2011;4:75-81.

9. Ouzaid I, Hermieu J-F, Misraï V. Transvaginal repair of genital prolapse using the Prolift technique: A prospective study [in French]. Prog Urol 2010;20:578-83. http://dx.doi.org/10.1016/i.purol.2010.01.013

10. Jia $X$, Glazener $C$, Mowatt $G$. Efficacy and safety of using mesh or grafts in surgery for anterior and/or posterior vaginal wall prolapse: Systematic review and meta-analysis. BJOG 2008;1 15:1350-61. httrp:// dx.doi.org/10.1111/i.1471-0528.2008.01845.x

11. Altman D, Zetterström J, Mellgren A. A three-year prospective assessment of rectocele repair using porcine xenograft. Obstet Gynecol 2006;107:59-65. http://dx.doi.org/10.1097/01. AOG.0000192547.58102.ab

12. Debodinance $P$, Amblard J, Fatton $B$. The prosthetic kits in the prolapse surgery: Is it a gadget? [in French]. J Gynecol Obstet Biol Reprod (Paris) 2007;36:267-75. http://dx.doi.org/10.1016/i. igyn.2007.02.018

13. Roumeguère T. Choice of prosthesis in genital prolapse surgery [in French]. Prog Urol 2005;15:1042-5.

14. Cobb WS, Burns JM, Peindl RD. Textile analysis of heavy weight, mid-weight, and light weight polypropyene mesh in a porcine ventral hernia model. J Surg Res 2006;136:1-7. http://dx.doi.org/10.1016/i. jss.2006.05.022

15. Fatton B, Savary D, Amblard J. How to manage multicompartment pelvic organe prolapse? [in French]. Prog Urol 2009;19:1086-97. http://dx.doi.org/10.1016/i.purol.2009.10.002

16. Beer M, Kuhn A. Surgical techniques for vault prolapse: A review of the literature. Eur J Obstet Gynecol Reprod Biol 2005;119:144-55. http://dx.doi.org/10.1016/i.ejogrb.2004.06.042

17. Sze EH, Karram MM. Transvaginal repair of vault prolapse: A review. Obstet Gynecol 1997;89:466-75. http://dx.doi.org/10.1016/S0029-7844(96)00337-7

18. Ganatra AM, Rozet F, Sanchez-Salas R. The current status of laparoscopic sacrocolpopexy: A review. Eur Urol 2009;55:1089-103. http://dx.doi.org/10.1016/i.eururo.2009.01.048

19. Vaiyapuri GR, Han HC, Lee LC. Retrospective study of transobturator polypropylene mesh kit for the management of pelvic organ prolapse. Singapore Med J 2012;53:664-70.
20. Urdzik P, Galád J, Ostró A. Risk of the prolapse « de novo » in primary unaffected compartment by using the syntethic mesh in the surgery treatment of the pelvic organe prolapse [in Slovak]. Ceska Gynekol 2011;76:321-6.

21. Debodinance P, Berrocal J, Clavé H. Changing attitudes on the surgical treatment of urogenital prolapse: Birth of the tension-free vaginal mesh [in French]. J Gynecol Obstet Biol Reprod (Paris) 2004;33:577-88. http://dx.doi.org/10.1016/S0368-2315(04)96598-2

22. Fatton B. Conséquences sexuelles de la chirurgie du prolapsus. Prog Urol 2009;19:1037-59. http:// dx.doi.org/10.1016/i.purol.2009.10.001

23. Sivaslioglu AA, Unlubilgin $\mathrm{E}$, Dolen I. A randomized comparison of polypropylene mesh surgery with sitespecific surgery in the treatment of cystocoele. Int Urogynecol J Pelvic Floor Dysfunct 2008;19:467-71. http://dx.doi.org/10.1007/s00192-007-0465-y

24. Meschia $M$, Piffarotti $P$, Bernasconi $F$. Porcine skin collagen implants to prevent anterior vaginal wall prolapse recurrence: A multicenter, randomized study. J Urol 2007;177:192-5. http://dx.doi.org/10.1016/i. juro.2006.08.100

25. Nieminen K, Hiltunen R, Heiskanen E. Symptom resolution and sexual function after anterior vaginal wall repair with or without polypropylene mesh. Int Urogynecol J Pelvic Floor Dysfunct 2008;19:1611-6. httr://dx.doi.org/10.1007/s00192-008-0707-7

26. Ghafar MA, Chesson RR, Velasco C. Size of urogenital hiatus as a potential risk factor for emptying disorders after pelvic prolapse repair. J Urol 2013;190:603-7. http://dx.doi.org/10.1016/i.juro.2013.02.020

27. Kaufman Y, Singh SS, Alturki H. Age and sexual activity are risk factors for mesh exposure following transvaginal mesh repair. Int Urogynecol J 2011;22:307-13. http://dx.doi.org/10.1007/s00192010-1270-6

28. Huffaker RK, Shull BL, Thomas IS. A serious complication following placement of posterior Prolift. Int Urogynecol J Pelvic Floor Dysfunct 2009;20:1383-5. http://dx.doi.org/10.1007/s00192-009-0873-2

29. Igniatovic I, Stosic D. Retrovesical haematoma after anterior Prolift procedure for cystocele correction. Int Urogynecol J Pelvic Floor Dysfunct 2007; 18:1495-7. http://dx.doi.org/10.1007/s00192-007-0396-7

30. Khandwala S, Jayachandran C. Transvaginal mesh surgery for pelvic organ prolapse-Prolift+M: A prospective clinical trial. Int Urogynecol J 2011;22:1405-11. http://dx.doi.org/10.1007/s00192-01 1-1482-4

Correspondence: Dr. Sébastien Kozal, Département d'Urologie-Andrologie, CHU Reims, Avenue du Général Koenig, 51092 Reims, France; sebastien.kozal@gmail.com 